\title{
Lifetime Attributable Risk Estimates of Secondary Cancer after External Radiotherapy among Colorectal Cancer Survivors in Saudi Arabia
}

Fouad Abolaban ( $\square$ fabolaban@kau.edu.sa )

King Abdulaziz University

Fathi Djouider

King Abdulaziz University

\section{Research Article}

Keywords: Colorectal cancer, Radiotherapy, Organ dose, Second cancer incidence, Lifetime attributable risk

Posted Date: June 8th, 2021

DOI: https://doi.org/10.21203/rs.3.rs-574208/v1

License: (c) (i) This work is licensed under a Creative Commons Attribution 4.0 International License.

Read Full License 


\title{
Lifetime Attributable Risk Estimates of Secondary Cancer after External Radiotherapy among Colorectal Cancer Survivors in Saudi Arabia
}

\author{
Fouad A. Abolaban* and Fathi M. Djouider \\ Nuclear Engineering Department, Faculty of Engineering, King Abdulaziz \\ University, Po Box 80204, Jeddah, 21589, Saudi Arabia \\ *(corresponding author: e-mail: fabolaban@kau.edu.sa).
}

\begin{abstract}
Radiation-induced second cancer is one of the crucial late side effects of radiotherapy treatment of first cancer. Although the second cancer induction mechanism is not well understood yet, many factors are related to its occurrences, such as age at exposure, dose to the organ and surrounding tissues, treatment modalities, and family history of cancer. This study aims to provide long-term estimates of second cancer incidence amongst colon cancer survivors in Saudi Arabia. The lifetime attributable risk (LAR) after radiation treatment of the colon cancer was determined, between the age at exposure and up to 95 years, in a single-institution cohort of male and female cancer survivors whose age at treatment was in the range 43 to 85 years. Risk estimates varied significantly with age at exposure, gender, and organ dose.
\end{abstract}

Keywords: Colorectal cancer; Radiotherapy; Organ dose; Second cancer incidence; Lifetime attributable risk 


\section{Introduction}

Colon cancer and rectal cancer, grouped as colorectal cancer (CRC), are the third and second most frequently occurring cancers across the world in men and women, respectively, and the second deadliest malignancy for both sexes combined. In 2020 over 1.9 million new CRC cases were diagnosed worldwide. With over 0.9 million deaths, CRC remained the second cause of cancer death after lung cancer for both sexes ${ }^{1}$. The highest incidence rates have been found in Australia, New Zealand, Canada, the United States, and the lowest in China, India, Africa, and South America. Both genetic and environmental factors play an essential part in the etiology of CRC ${ }^{2}$. Most CRC are erratic and strongly linked to environmental factors where obesity, smoking, consumption of processed meat, and alcoholic drinks are the main factor risks. They present striking dissimilarities amongst races and ethnic groups. Clinical indications showed they are relatively unusual before the age of 50 and commonly evolve, in a 10 to 15 -year period, from adenomatous polyps to invasive carcinoma ${ }^{3,4}$. Few of the CRC are attributed to inherited syndromes and familial clustering in the lack of recognizable inherited syndrome. Survival rates have drastically increased over the past three decades, especially in developed countries, owing to continuous progress in the prevention, early-stage diagnosis, and treatment ${ }^{5}$.

\subsection{CRC types}

The transformation of the normal colonic epithelium to a precancerous lesion (adenoma) and ultimately to invasive carcinoma requires an accumulation of genetic mutations, either somatic and/or germline ${ }^{6}$. CRC can be categorized in three main molecular pathways based on the somatic and genetic disruptions in DNA repair pathways ${ }^{7-9}$

- Chromosomal instability (CIN) is described by an aneuploidy subchromosomal genomic amplifications and a high frequency of loss of heterozygosity in tumor suppressor genes or protooncogenes such as TP53 or KRAS, respectively. This more aggressive multistep carcinogenesis cancer is the most common, around $70 \%$, of all the sporadic CRC ${ }^{10}$.

- Microsatellite instability (MSI) pathway due to loss of DNA repair mechanisms affecting coding microsatellites in mismatch repair genes such as $M L H 1$, MSH2, MSH6, PMS1 and PMS2. There is a growing body of evidence showing that hypermethylation of $\mathrm{CpG}$ islands in these genes inhibits their expressions ${ }^{11-14}$. This heritable germline mutation, found in Lynch syndrome, a hereditary non-polyposis colorectal cancer (HNPCC), is responsible for $20 \%$ of CRC

- Epigenetic instability $\mathrm{CpG}$ island methylator phenotype (CIMP) pathway caused by the hypermethylation of protooncogenes and tumor suppressor genes leading to the inhibition 
of their genetic expressions. This gene silencing pathway is responsible for $10 \%$ of all CRC 15 .

\subsection{Biological pathways of CRC induction}

Radiation-induced cancer is a slow and multistep process. There is a growing body of evidence showing that the risk of developing a second cancer in the irradiated tissue or the adjacent organs is conceivable and increases over time ${ }^{16-18}$. Radiation exposure of the highly radiosensitive gastrointestinal track tissues to ionizing radiation induces, via inherent DNA damages and variety of cellular responses, a premature cell senescence promoting the transition from normal epithelium cells to malignant tumor cells in the colorectal site ${ }^{19-21}$. Oversecretion by senescent cells of cytokines (IL-1, IL-6, IL-7, IL-13), chemokines (CCL2, CXCL1, CXCL8, CXCL12), and growth factors (heregulin, EGF, bFGF, IGF, VEGF, TGF- $\beta 1$ ), activates the NF- $\mathrm{kB}$ nuclear transcription factor pathway to suppress cancer cell apoptosis, then contributing to the majority of CRC recurrence $(22,23$.

Furthermore, activation of NF- $\mathrm{kB}$ induces, via cytidine deaminase (AID), mutations in the tumor suppressor gene $T P 53^{24,25}$ making senescent cells escape growth inhibition checkpoints leading to accelerated colorectal tumorigenesis where TP53 mutations is present in $40 \%$ of CRC ${ }^{26}$.

\subsection{CRC incidence and mortality in Saudi Arabia}

In Saudi Arabia, the most common cancer diseases include breast, thyroid, and CRC. The latter is the highest and the third common cancer amongst men and women, respectively. The agestandardized incidence rates and age-standardization mortality rates for CRC are 13.1 and 6.3 cases per 100,000 people for both sexes ${ }^{27}$. Risk factors such as excess weight, sedentary lifestyle, diet rich in processed food, smoking, inflammatory bowel disease were found to contribute to $60-65 \%$ of CRC for both genders. Family history, due to the high rate of consanguineous marriage, and genetic syndrome (familial adenomatous polyposis or Lynch syndrome) account for $25-30 \%$ and $5 \%$, respectively ${ }^{27-29}$. Polymorphisms of the ADIPOQ ${ }^{30}$, XRCC1, RETN ${ }^{31}$, and vitamin D receptor VDR ${ }^{32}$ due to low vitamin $\mathrm{D}$ intake, have also been associated with increased risk CRC among Saudi older population.

To control the national CRC incidence, a large screening program targeting individuals from both genders aged 40 years and above was launched a decade ago ${ }^{33,34}$. However, public perception and lack of acceptance of screening colonoscopy for CRC remains the main obstacle for the success of this program.

Saudi patients diagnosed with an advanced stage of CRC are at younger ages (less than 50 years) when compared to Western populations. Mansoor et al. and Aljebreen reported that 39 and 37\%

of their patients were under 50 years old, respectively ${ }^{35,36}$. Al-Ahwal et al. reported that $29.7 \%$ of 
CRC Saudi patients were younger than 40 years old ${ }^{37}$. Population-based cancer incidence showed that CRC suffered the sharpest increase from age 40 years to 50 for both genders (4-fold and 3fold for male and females respectively), becoming a major healthcare burden ${ }^{38}$. 


\section{Methodology}

\subsection{Data collection}

The retrospective cohort study included eight males, ranged in age from 43 to 85 years, and twelve females ranging in age from 43 to 73 years all King Abdullah Medical City - Oncology center (Jeddah, Saudi Arabia) Cancer Registry 2016-2018, with a confirmed first CRC. They were subject to Linac-based intensity modulated radiation therapy (IMRT) with an average fractionated dose of 1.8 Gy for a total treatment dose ranging between 30 and 72 Gy. The dose delivery was generally well tolerated by the patients. Radiation exposure was ascertained by the effective dose (ranging from 3.6 to $8.4 \mathrm{~Sv}$ ), which quantifies the biologic effects of radiation absorbed by the anatomic region irradiated as determined by absorbed dose, radiation type, and energy (Table 1). The dose selection was based on patient-specific parameters such as the nature of the underlying condition, age, tumor size, and location.

Table 1: Data on patient attributes included in this study.

\begin{tabular}{cccc}
\hline Patient number & Age at exposure (years) & Gender & Organ dose (Sv) \\
\hline 1 & 85 & M & 3.6 \\
2 & 85 & M & 8.4 \\
3 & 74 & M & 6.1 \\
4 & 73 & F & 5.4 \\
5 & 65 & F & 5.4 \\
6 & 64 & F & 6.1 \\
7 & 64 & F & 6.1 \\
8 & 61 & M & 6.1 \\
9 & 60 & F & 5.4 \\
10 & 59 & M & 6.1 \\
11 & 56 & F & 6.7 \\
12 & 52 & F & 5.4 \\
13 & 51 & F & 5.4 \\
14 & 50 & F & 5.4 \\
15 & 48 & M & 6.1 \\
16 & 48 & F & 6.1 \\
17 & 44 & F & 5.4 \\
18 & 44 & M & 6.1 \\
19 & 43 & F & 5.4 \\
20 & 43 & M & 5.4 \\
\hline
\end{tabular}




\subsection{Modeling of risk estimations}

$\mathrm{CRC}$ has been noticeably correlated with radiation exposure in Hiroshima and Nagasaki A-bomb survivors data during the period $1950-2000{ }^{39}$. Furthermore, several large epidemiologic studies and predictive models have shown that long-term survivors of colon radiotherapy have an increased incidence of second cancer, mainly located within or close to the primary cancer treatment field ${ }^{40-42}$. Based on this, a number of risk models have been developed by national and international bodies to estimate second CRC incidence risks: the International Committee on Radiation Protection (ICRP) the United Nations Scientific Committee on the Effects of Atomic Radiation (UNSCEAR), the Biological Effect of Ionizing Radiation (BEIR VII) and the Environmental Protection Agency (EPA). The uncertainties associated with each of the models are close to or exceed the variation between the models ${ }^{43}$.

\subsection{Application of the BEIR risk model to $C R C$ incidence}

Although initially developed for low-dose radiation exposures, we used the BEIR VII linear nothreshold (LNT) model to estimate the probabilistic risk of a second CRC associated with high fractionated radiotherapy doses, as it provides parameters for specific organs for each sex as well as parameters describing incidence with age at exposure and attained age. The BEIR VII cancer risk is expressed using both multiplicative and additive models ${ }^{44}$. In the multiplicative model, the incremental site-specific cancer risk is proportional to baseline rates. In the additive model, the risk increment is independent of the baseline rates but adds to it. To the best of our knowledge, this is the very first study to address the occurrence of second CRC amongst Saudi cancer survivors following external radiotherapy.

For all solid carcinogens, it is generally agreed that the risk increases with dose with a latency period of 5 years ${ }^{44}$. Both excess absolute risk and excess relative risk of secondary solid cancer were calculated according to

$$
\begin{gathered}
E A R \text { and } E R R=\beta_{S}(O E D) e^{\gamma e^{*}}\left(\frac{a}{60}\right)^{\eta} \\
e^{*}=\frac{(e-30)}{10} \text { for } e<30 \text { and } 0 \text { for e }>30 \text { years }
\end{gathered}
$$

where $e$ is the age at exposure (years), $a=e+L$ is the attained age (years), $L$ the minimum latency period at which a solid cancer might occur following radiotherapy treatment (5 years for solid cancers). $\beta_{s}, \gamma$ and $\eta$ are the BEIR VII specific cancer risk coefficients associated with sex, age at exposure and attained age, respectively. There is no increase in risk in the absence of exposure i.e both $\mathrm{ERR}$ and $\mathrm{EAR}=0$.

The LAR describes the probability that an irradiated person would develop a second cancer during his/her lifetime (total projected second cancer risk). It is calculated over the age range of $(e+L)$ to 95 years using the values of $E A R$ and $E R R$ 


$$
L A R=\left(\sum_{a}^{95} E R R \cdot \lambda_{a}^{S} \cdot \frac{S(a)}{S(e)}\right)^{0.7} \times\left(\sum_{a}^{95} E A R \cdot \frac{S(a)}{S(e)}\right)^{0.3}
$$

$\lambda_{a}^{S}$ is the baseline cancer rate, i.e. the cancer rate incidence in the absence of irradiation, which depends on sex $(s)$ and attained age $(a), S(a)$ is the probability of surviving until age $a$, and $\frac{S(a)}{S(e)}$ is the probability of a healthy individual of surviving to age $a$ conditional on survival to exposed age $e$. Values of $\lambda_{a}^{s}$ were taken from the Saudi National Health Information Center - Cancer Registry (NHIC). An average value of $44.6 \%$ for both males and females was taken for the value of $\frac{S(a)}{S(e)} 45$. Projections of the lifetime risk of CRC, are weighted in the logarithmic space by 0.7 and 0.3 , for the additive and multiplicative models, respectively (BEIR). The coefficients used for estimating ERR and EAR of developing a second CRC are given in Table 2. Data entry and processing were performed using Excel 2010 by Microsoft.

Table 2: Coefficients of the BEIR VII cancer risk model for CRC

\begin{tabular}{cccccc}
\hline Model & $\boldsymbol{\omega}$ & $\boldsymbol{\beta}_{\boldsymbol{M}}$ & $\boldsymbol{\beta}_{\boldsymbol{F}}$ & $\boldsymbol{\gamma}$ & $\boldsymbol{\eta}$ \\
\hline $\boldsymbol{E R \boldsymbol { R }}$ & 0.7 & 0.63 & 0.43 & -0.30 & -1.4 \\
$\boldsymbol{E} \boldsymbol{A} \boldsymbol{R}$ & 0.3 & 3.2 & 1.6 & -0.41 & 2.8 \\
\hline
\end{tabular}

The age-specific incidence rate (ASIR), or baseline prevalence, by five-year age groups for both male and female Saudi population diagnosed with CRC is shown in Table 3 (NHIC).

Table 3: Baseline CRC incidence rate among Saudi population.

\begin{tabular}{ccc}
\hline & \multicolumn{2}{c}{$\lambda$ baseline incidence rate for CRC } \\
\hline Age group & Male (per 100,000 population) & Female (per 100,000 population) \\
\hline $40-45$ & 10.2 & 10.1 \\
$45-50$ & 20.4 & 19.2 \\
$50-55$ & 34.2 & 30.1 \\
$55-60$ & 45.1 & 45.3 \\
$60-65$ & 51.2 & 50.7 \\
$65-70$ & 87.2 & 49.4 \\
$70-75$ & 89.1 & 48.1 \\
$75-80$ & 89.7 & 47.7 \\
\hline
\end{tabular}




\section{Results and discussion}

The risk of secondary CRC amongst patients caused by first cancer radiotherapy treatment is an area of debate in clinical radiation oncology. The biggest challenge in evaluating the second CRC risk is the latency period of onset following initial radiotherapy treatment ${ }^{46-48}$. This recurrence is expected to occur many years after the first diagnosis ${ }^{49}$. This time interval between the first treatment and secondary malignancy development is the primary source of uncertainty and makes the risk difficult to be measured and impractical to test through large prospective clinical trials. Although the ERR and EAR have the same expression, the values and interpretation of their respective parameters are different. In particular, the ERR shows a decrease with attained age, while the EAR shows a substantial increase with attained age for both males and females (Figure 1 to Figure 4). However, a decrease in both ERR and the EAR with increasing age at exposure is observed.

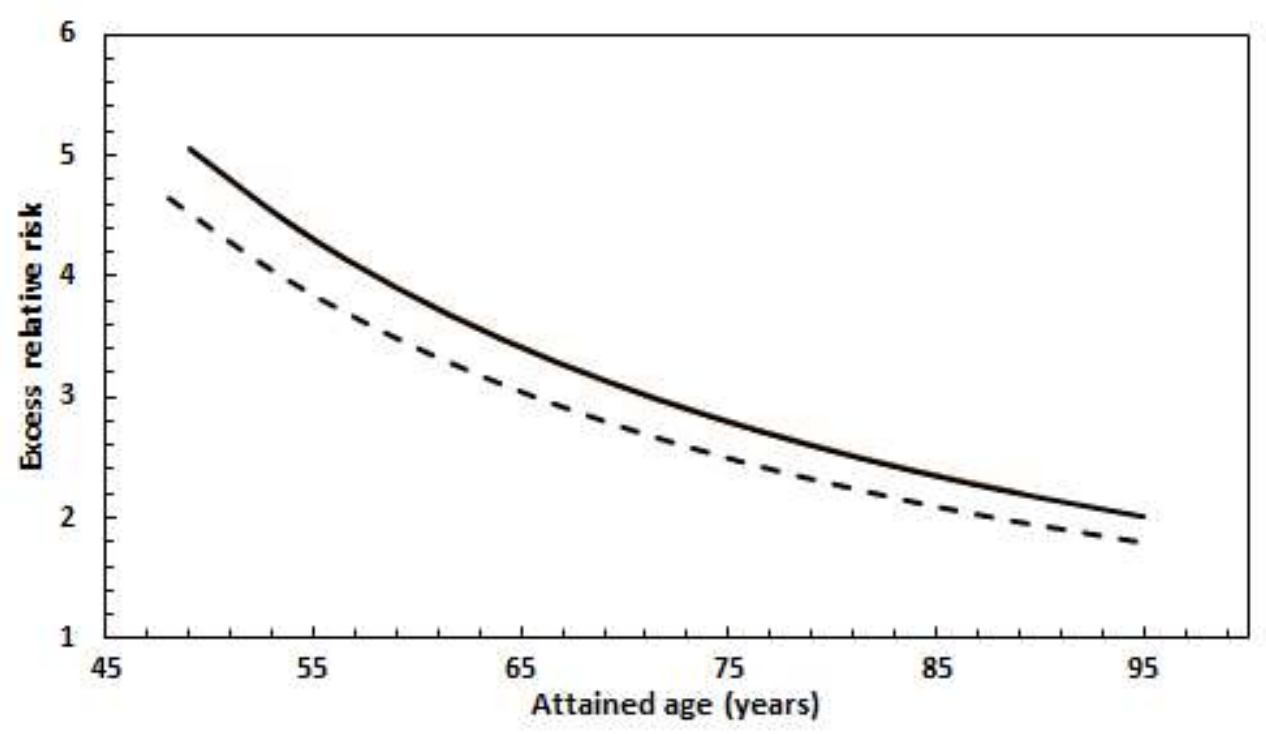

Figure 1: Excess relative risk of two male patients: age at exposure: (-- -) 43 years, irradiation dose: $5.4 \mathrm{~Sv}$, and (一) age at exposure: 44 years, organ dose: $6.1 \mathrm{~Sv}$. 


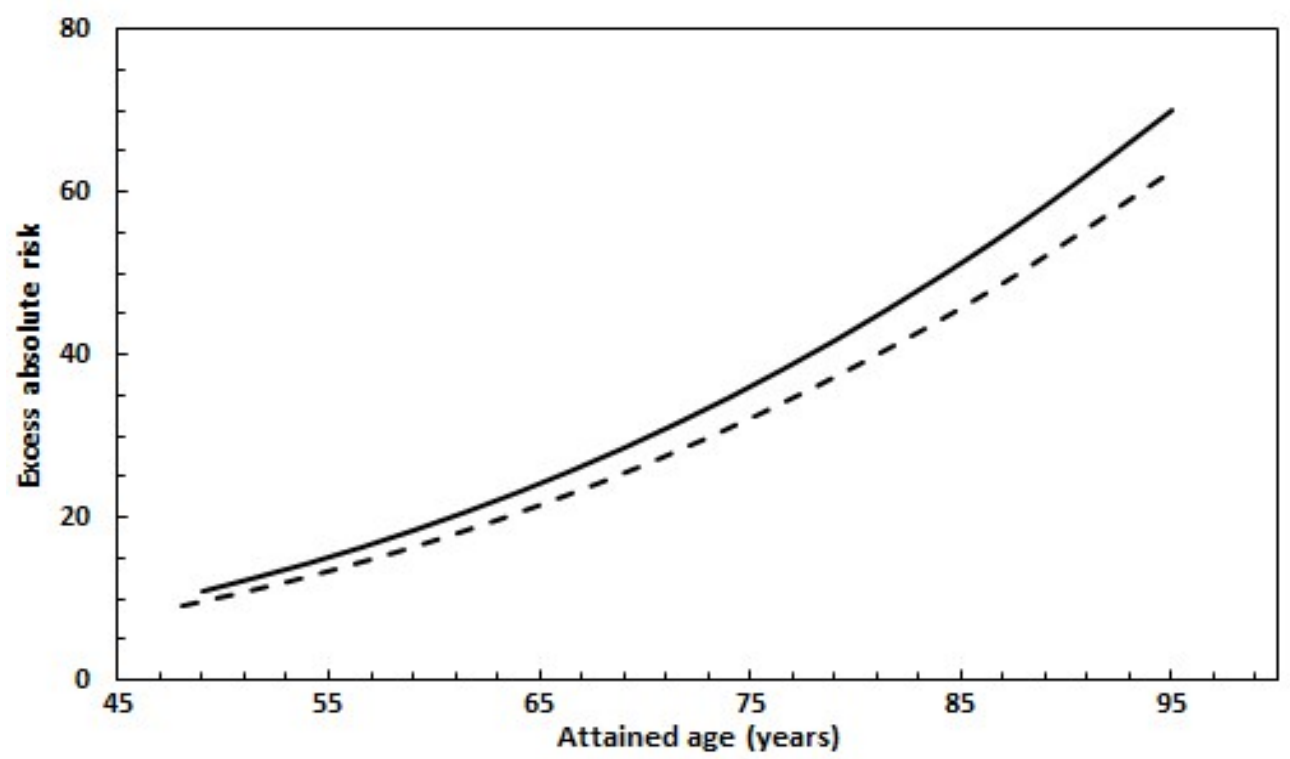

Figure 2: Excess absolute risk of two male patients: (-- ) age at exposure: 43 years, irradiation dose: $5.4 \mathrm{~Sv}$, and (-) age at exposure: 44 years, irradiation dose: $6.1 \mathrm{~Sv}$.

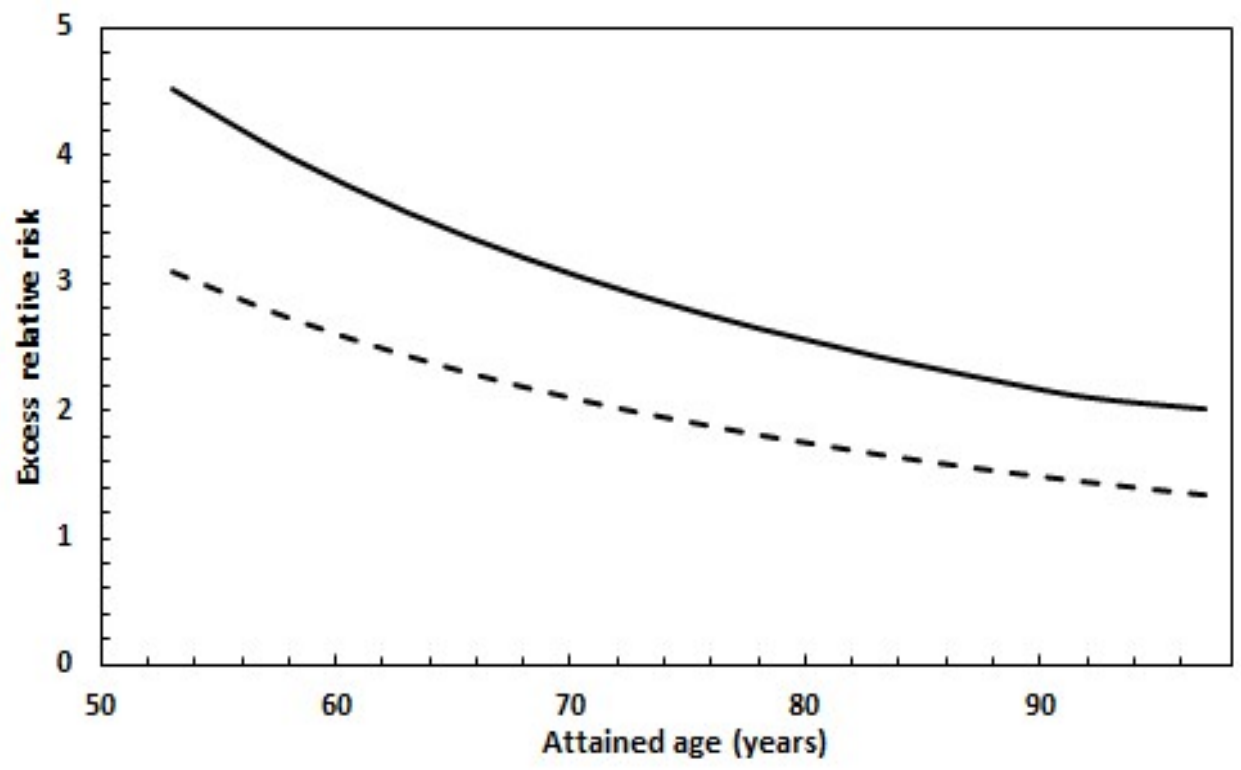

Figure 3: Excess relative risk of male (-) and female (- - ) patients with same age at exposure (48 y) and same irradiation dose (6.1 Sv). 


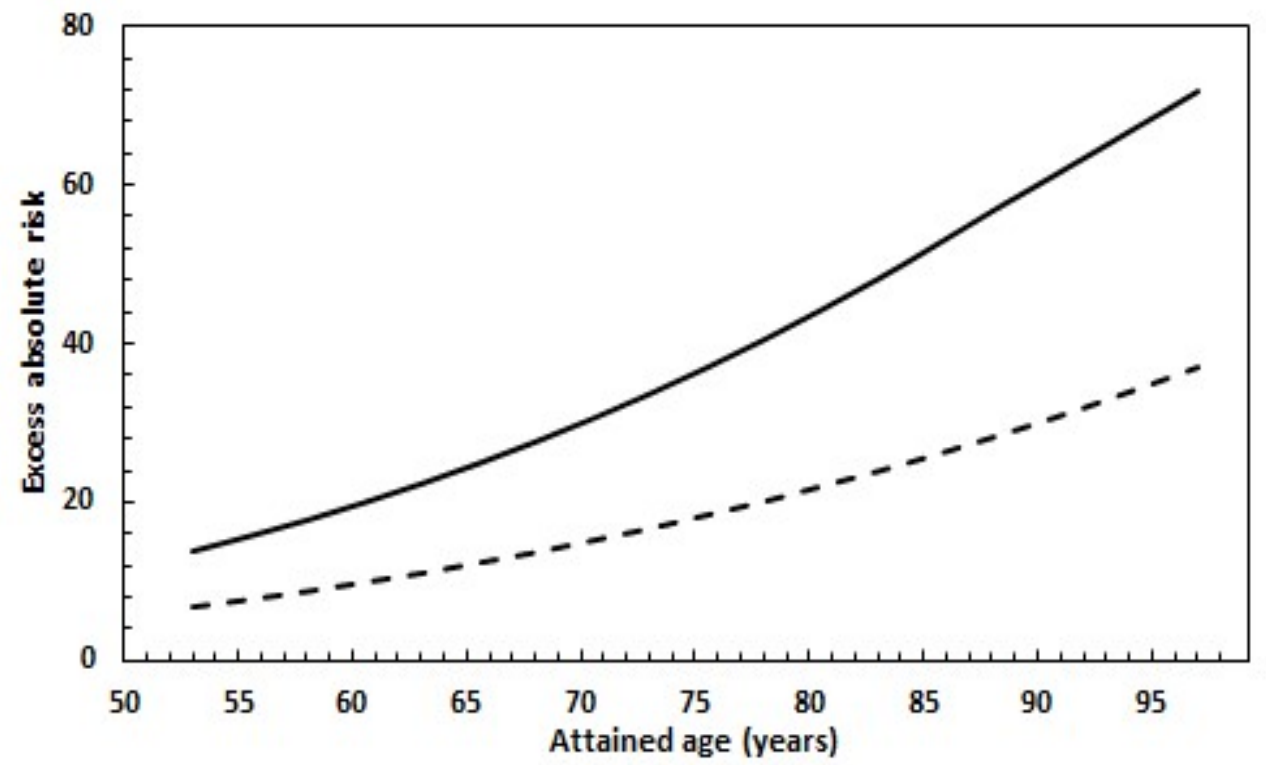

Figure 4: Excess absolute risk of male (-) and female (- - ) patients with same age at exposure $(48 \mathrm{y})$ and same irradiation dose $(6.1 \mathrm{~Sv})$.

In addition to the occurrence of cancer in sex-specific organs such as the prostate and ovary, growing evidence shows that $\mathrm{CRC}$ incidence and mortality is more predominant in males than in females. This inequality is probably due to differences in environmental exposures, estrogen level between men and women, and possibly complex interactions between these effects 50. Women are more prone to right-sided higher severity tumor while men exhibited the tumor more on the left side ${ }^{51}$. Our results show that both ERR and EAR estimates are higher for males than those for females (Figures 3 and 4) as affected by the CRC baseline incidence rate among the Saudi population (NHIC, 2015). Both ERR and EAR increased with organ dose independently of the gender (Figures 1 and 2).

Being the large risk metric in second CRC risk estimates, the computation of LAR can be performed for each exposed patient, considering the parameters $s$ (sex), $D$ (exposure dose), $e$ (age at exposure), and $a$ (attained age). Alternatively, it can be computed for an exposed population considering a set of assumptions regarding genetic or environmental risk factors ${ }^{44}$. The first option was chosen in this study owing to the lack of genetic or environmental data of our cluster patients. Our results show that both male and female CRC survivors had an elevated LAR of developing a second cancer for all age groups, compared to the particular baseline cancer risks incidence (Tables 4 and 5). The LAR data show an inverse correlation to age at exposure. In female patients, more than 5-fold decrease in LAR from age at exposure of 43 years to that at 73 years for the same organ dose of 5.4 Sv (Figure 5). The same trend is observed amongst male patients where for instance, 3.6-fold decrease in LAR from age at exposure of 4 years to that at 74 years for the same organ 
dose of 6.1 Sv (Figure 6). The fact that a higher CRC risk is observed amongst young patients is particularly due to longer residual life expectancy and various other aspects such as genetic predisposition, risk factor, etc. ${ }^{52,53}$.

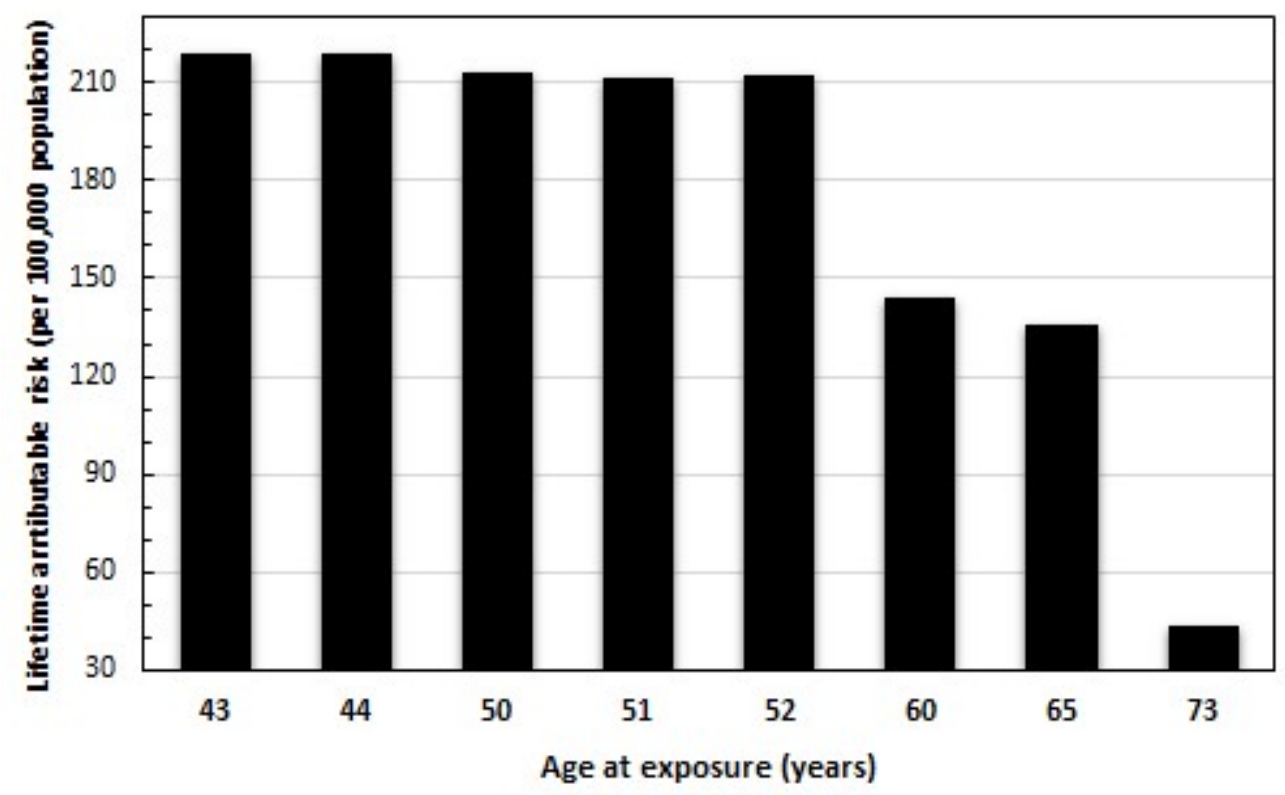

Figure 5: Female cumulated lifetime attributable risk of colorectal cancer per 100,000 population. Irradiation dose: $5.4 \mathrm{~Sv}$.

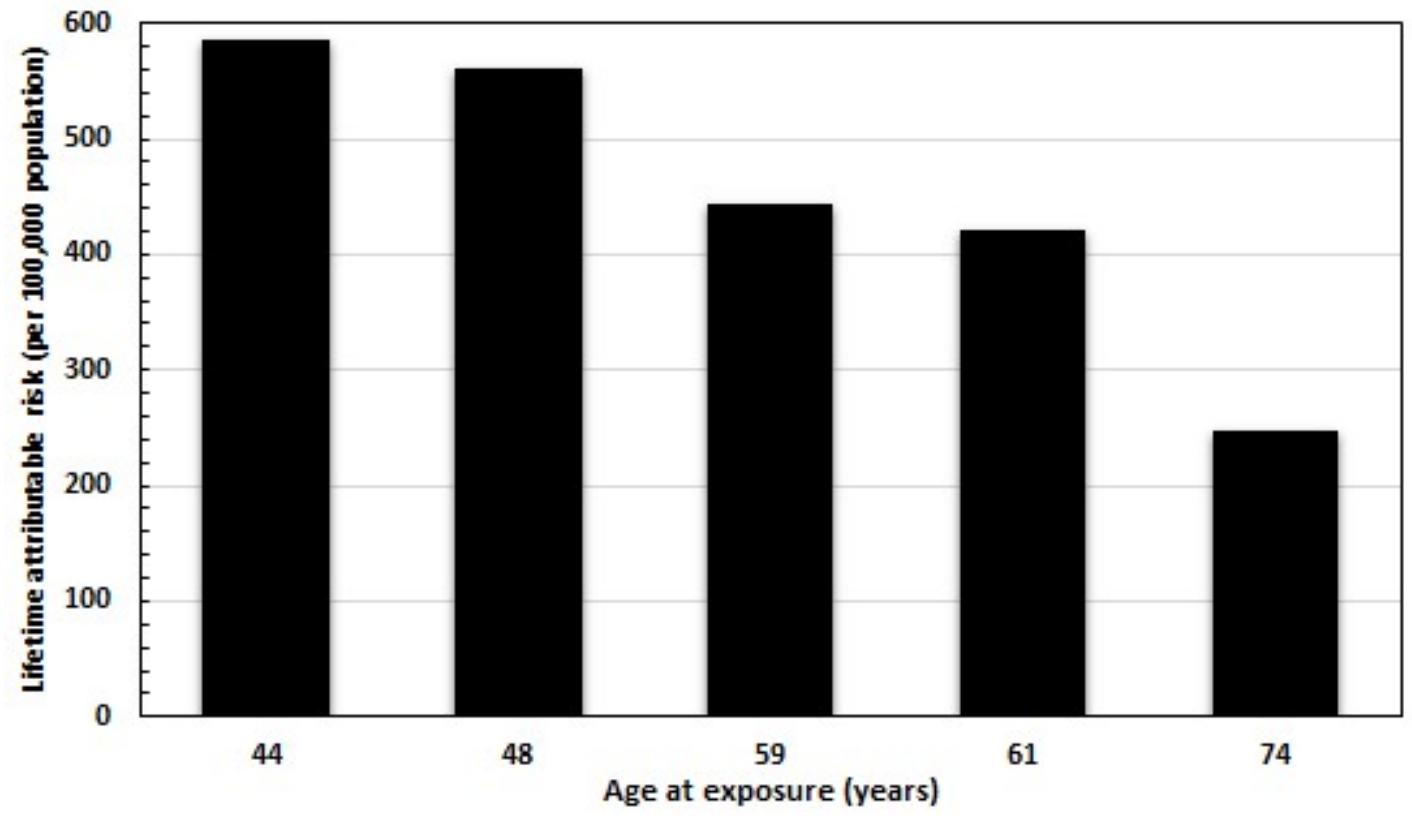

Figure 6: Male cumulated lifetime attributable risk of colorectal cancer per 100,000 population. Irradiation dose: $6.1 \mathrm{~Sv}$. 
The results from this study should be interpreted with extreme caution. Estimating the risk of second malignancy among CRC survivors following radiotherapy would help healthcare providers to identify appropriate prevention strategies, bearing in mind that $20 \%$ of all cancer patients develop during their lives recurrent tumors ${ }^{54}$.

Table 4: Estimated LAR of radiation-induced CRC among female and male patients.

\begin{tabular}{ccccc}
\hline $\begin{array}{c}\text { Patient } \\
\text { number }\end{array}$ & $\begin{array}{c}\text { Age at exposure } \\
\text { (years) }\end{array}$ & $\begin{array}{c}\text { Organ } \\
\text { dose (Sv) }\end{array}$ & $\begin{array}{c}\text { LAR } \\
\text { (per 100,000 population) }\end{array}$ & $\begin{array}{c}\text { Baseline incidence rate } \\
\text { (per 100,000 population) }\end{array}$ \\
\hline 1 & 43 & 5.4 & 219.2 & 10.1 \\
2 & 44 & 5.4 & 218.4 & 10.1 \\
3 & 48 & 6.1 & 257.5 & 19.2 \\
4 & 50 & 5.4 & 213.4 & 30.1 \\
5 & 51 & 5.4 & 211.8 & 30.1 \\
6 & 52 & 5.4 & 212.0 & 30.1 \\
7 & 56 & 6.7 & 265.5 & 45.3 \\
8 & 60 & 5.4 & 144.3 & 50.7 \\
9 & 64 & 6.1 & 152.1 & 50.7 \\
10 & 64 & 6.1 & 152.1 & 50.7 \\
11 & 65 & 5.4 & 135.5 & 49.4 \\
12 & 73 & 5.4 & 43.6 & 47.7 \\
\hline
\end{tabular}

Table 5: Estimated LAR of radiation induced CRC among female male patients.

\begin{tabular}{ccccc}
\hline $\begin{array}{c}\text { Patient } \\
\text { number }\end{array}$ & $\begin{array}{c}\text { Age at exposure } \\
\text { (years) }\end{array}$ & $\begin{array}{c}\text { Organ } \\
\text { dose (Gy) }\end{array}$ & $\begin{array}{c}\text { LAR } \\
\text { (per 100,000 population) }\end{array}$ & $\begin{array}{c}\text { Baseline incidence rate } \\
\text { (per 100,000 population) }\end{array}$ \\
\hline 1 & 43 & 5.4 & 466.2 & 10.2 \\
2 & 44 & 6.1 & 521.2 & 10.2 \\
3 & 48 & 6.1 & 498.4 & 20.4 \\
4 & 59 & 6.1 & 443.2 & 45.1 \\
5 & 61 & 6.1 & 420.4 & 51.2 \\
6 & 74 & 6.1 & 246.9 & 89.1 \\
7 & 85 & 8.6 & 173.5 & 47.7 \\
8 & 85 & 3.6 & 72.3 & 47.7 \\
\hline
\end{tabular}




\section{Conclusion}

In this study, we estimated the incidence of secondary cancer recurrence resulting from external radiotherapy of primary CRC. However, applying the BEIR or any other model in predicting the occurrence of secondary radiation-induced cancer in a cancer survivor population is constrained by a lack of knowledge in some areas such as biological and genetic mechanisms related to carcinogenesis, uncertainties in radiation dosimetry, partial or failure in out-patients follow-up.

\section{Acknowledgment}

This project was funded by the Deanship of Scientific Research (DSR) at King Abdulaziz University, Jeddah, under grant no. RG-12-135-40. The authors, therefore, gratefully acknowledge DSR technical and financial support.

\section{Ethics approval}

We can confirm that this retrospective study, involving patient diagnosed with CRC, was approved by the Saudi National Committee on Bioethics (NCBE) in accordance with its ethical standards of its research committee. Furthermore, informed consent was obtained from each patient (or his/her legal representative) after being informed about the nature of research.

\section{Glossary}

Baseline incidence rates of cancer in a given population:

Cancer incidence rate in an unexposed cohort

Excess Absolute Risk, EAR(t):

the difference between incidence rates of an exposed cohort and an unexposed cohort. It designates the excess increase in incidence rate associated with radiation exposure.

$$
E A R(t)=\delta_{E}(t)-\delta_{U}(t)
$$

Relative Risk RR(t):

Defined as the ratio between incidence rates of an unexposed and an unexposed cohort:

$$
\operatorname{ERR}(t)=\frac{\delta_{E}(t)}{\delta_{U}(t)}
$$


If exposure increases the risk, then $E R R(t)>1$; if exposure decreases the risk, then $E R R(t)<1$, and $E R R(t)=1$ corresponds to the case where no correlation exists between the cancer risk and the radiation exposure.

Excess Relative Risk ERR(t):

proportion of $\mathrm{RR}(\mathrm{t})$ attributable only to radiation exposure

$$
\operatorname{ERR}(\mathrm{t})=\operatorname{RR}(\mathrm{t})-1=\frac{\delta_{E}(t)-\delta_{U}(t)}{\delta_{U}(t)}
$$

\section{References}

1. Bray, F. et al. Global cancer statistics 2018: GLOBOCAN estimates of incidence and mortality worldwide for 36 cancers in 185 countries. CA. Cancer J. Clin. 68, 394-424 (2018).

2. Rattray, N. J. W. et al. Environmental Influences in the Etiology of Colorectal Cancer: the Premise of Metabolomics. Current Pharmacology Reports vol. 3 114-125 (2017).

3. Bujanda, L., Cosme, A., Gil, I. \& Arenas-Mirave, J. I. Malignant colorectal polyps. World J. Gastroenterol. 16, 3103-3111 (2010).

4. Sievers, C. K., Grady, W. M., Halberg, R. B. \& Pickhardt, P. J. New insights into the earliest stages of colorectal tumorigenesis. Expert Review of Gastroenterology and Hepatology vol. 11 723-729 (2017).

5. Conteduca, V., Sansonno, D., Russi, S. \& Dammacco, F. Precancerous colorectal lesions (Review). International Journal of Oncology vol. 43 973-984 (2013).

6. Testa, U., Pelosi, E. \& Castelli, G. Colorectal Cancer: Genetic Abnormalities, Tumor Progression, Tumor Heterogeneity, Clonal Evolution and Tumor-Initiating Cells. Med. Sci. 6, 31 (2018).

7. Al-Sohaily, S., Biankin, A., Leong, R., Kohonen-Corish, M. \& Warusavitarne, J. Molecular pathways in colorectal cancer. Journal of Gastroenterology and Hepatology (Australia) vol. 27 1423-1431 (2012).

8. Neumann, J. H. L., Jung, A. \& Kirchner, T. Molekulare Pathologie des kolorektalen Karzinoms. Pathologe 36, 137-144 (2015).

9. Dawson, H. \& Lugli, A. Molecular and pathogenetic aspects of tumor budding in colorectal cancer. Frontiers in Medicine vol. 211 (2015).

10. Calistri, D. et al. KRAS, p53 and BRAF gene mutations and aneuploidy in sporadic colorectal cancer progression. Cell. Oncol. 28, 161-166 (2006).

11. Hanley, M. P. et al. Genome-wide DNA methylation profiling reveals cancer-associated changes within early colonic neoplasia. Oncogene 36, 5035-5044 (2017).

12. Berg, M., Hagland, H. R. \& Søreide, K. Comparison of CpG Island Methylator Phenotype (CIMP) Frequency in Colon Cancer Using Different Probe- and Gene-Specific Scoring Alternatives on Recommended Multi-Gene Panels. PLoS One 9, e86657 (2014).

13. Niessen, R. C. et al. Germline hypermethylation of MLH1 and EPCAM deletions are a frequent cause of Lynch syndrome. Genes Chromosom. Cancer 48, 737-744 (2009).

14. Kane, M. F. et al. Methylation of the hMLH1 promoter correlates with lack of expression of hMLH1 in sporadic colon tumors and mismatch repair-defective human tumor cell 
lines. Cancer Res. 57, 808-811 (1997).

15. Lao, V. V.\& Grady, W. M. Epigenetics and colorectal cancer. Nature Reviews Gastroenterology and Hepatology vol. 8 686-700 (2011).

16. Guren, M. G. et al. Reirradiation of locally recurrent rectal cancer: A systematic review. Radiotherapy and Oncology vol. 113 151-157 (2014).

17. Zhu, Z. et al. Risk of secondary rectal cancer and colon cancer after radiotherapy for prostate cancer: a meta-analysis. International Journal of Colorectal Disease vol. 33 1149-1158 (2018).

18. Rombouts, A. J. M. et al. Increased risk for second primary rectal cancer after pelvic radiation therapy. Eur. J. Cancer 124, 142-151 (2020).

19. Mikula-Pietrasik, J. et al. Colorectal cancer-promoting activity of the senescent peritoneal mesothelium. Oncotarget 6, 29178-29195 (2015).

20. Bartkova, J. et al. Oncogene-induced senescence is part of the tumorigenesis barrier imposed by DNA damage checkpoints. Nature 444, 633-637 (2006).

21. Pribluda, A. et al. A Senescence-inflammatory switch from cancer-inhibitory to cancerpromoting mechanism. Cancer Cell 24, 242-256 (2013).

22. Lin, W. W. \& Karin, M. A cytokine-mediated link between innate immunity, inflammation, and cancer. Journal of Clinical Investigation vol. 117 1175-1183 (2007).

23. Coppé, J. P., Desprez, P. Y., Krtolica, A. \& Campisi, J. The senescence-associated secretory phenotype: The dark side of tumor suppression. Annual Review of Pathology: Mechanisms of Disease vol. 5 99-118 (2010).

24. Matsumoto, Y. et al. Helicobacter pylori infection triggers aberrant expression of activation-induced cytidine deaminase in gastric epithelium. Nat. Med. 13, 470-476 (2007).

25. Kim, S. B. et al. Radiation promotes colorectal cancer initiation and progression by inducing senescence-associated inflammatory responses. Oncogene 35, 3365-3375 (2016).

26. Oh, H. J. et al. p53 expression status is associated with cancer-specific survival in stage III and high-risk stage II colorectal cancer patients treated with oxaliplatin-based adjuvant chemotherapy. Br. J. Cancer 120, 797-805 (2019).

27. Chaudhri, E., Fathi, W., Hussain, F. \& Hashmi, S. K. The increasing trends in cases of the most common cancers in Saudi Arabia. Journal of Epidemiology and Global Health vol. 10 258-262 (2020).

28. Almatroudi, A. $<\mathrm{p}>$ The Incidence Rate of Colorectal Cancer in Saudi Arabia: An Observational Descriptive Epidemiological Analysis $</ \mathrm{p}>$. Int. J. Gen. Med. Volume 13, 977-990 (2020).

29. Alqahtani, M. et al. Screening for Lynch syndrome in young Saudi colorectal cancer patients using microsatellite instability testing and next generation sequencing. Fam. Cancer 17, 197-203 (2018).

30. Al-Harithy, R. N. \& Al-Zahrani, M. H. The adiponectin gene, ADIPOQ, and genetic susceptibility to colon cancer. Oncol. Lett. 3, 176-180 (2012).

31. Alharithy, R. N. Polymorphisms in RETN gene and susceptibility to colon cancer in Saudi patients. Ann. Saudi Med. 34, 334-339 (2014).

32. Alkhayal, K. A. et al. Association of Vitamin D Receptor Gene Polymorphisms with Colorectal Cancer in a Saudi Arabian Population. PLoS One 11, e0155236 (2016).

33. Aljumah, A. A. \& Aljebreen, A. M. Policy of screening for colorectal cancer in Saudi 
Arabia: A prospective analysis. Saudi J. Gastroenterol. 23, 161-168 (2017).

34. Alsanea, N. et al. National Guidelines for Colorectal Cancer Screening in Saudi Arabia with strength of recommendations and quality of evidence. Ann. Saudi Med. 35, 189-195 (2015).

35. Aljebreen, A. M. Clinico-pathological patterns of colorectal cancer in Saudi Arabia: Younger with an advanced stage presentation. Saudi J. Gastroenterol. 13, 84-87 (2007).

36. Mansoor, I., Zahrani, I. H. \& Abdul Aziz, S. Colorectal cancers in Saudi Arabia. Saudi Med. J. 23, 322-327 (2002).

37. Al-Ahwal, M. \& Al-Ghamdi, A. Pattern of colorectal cancer at two hospitals in the western region of Saudi Arabia. Saudi J. Gastroenterol. 11, 164 (2005).

38. Bazarbashi, S., Al Eid, H. \& Minguet, J. Cancer incidence in Saudi Arabia: 2012 data from the Saudi cancer registry. Asian Pacific J. Cancer Prev. 18, 2437-2444 (2017).

39. Preston, D. L. et al. Effect of recent changes in atomic bomb survivor dosimetry on cancer mortality risk estimates. Radiat. Res. 162, 377-389 (2004).

40. Enblad, P., Adami, H. -O, Glimelius, B., Krusemo, U. \& Pahlman, L. The risk of subsequent primary malignant diseases after cancers of the colon and rectum a nationwide cohort study. Cancer 65, 2091-2100 (1990).

41. Birgisson, H., Påhlman, L., Gunnarsson, U. \& Glimelius, B. Occurrence of second cancers in patients treated with radiotherapy for rectal cancer. J. Clin. Oncol. 23, 6126-6131 (2005).

42. Baxter, N. N., Tepper, J. E., Durham, S. B., Rothenberger, D. A. \& Virnig, B. A. Increased risk of rectal cancer after prostate radiation: A population-based study. Gastroenterology 128, 819-824 (2005).

43. Donovan, E. M., James, H., Bonora, M., Yarnold, J. R. \& Evans, P. M. Second cancer incidence risk estimates using BEIR VII models for standard and complex external beam radiotherapy for early breast cancer. Med. Phys. 39, 5814-5824 (2012).

44. Walsh, L. \& Schneider, U. A method for determining weights for excess relative risk and excess absolute risk when applied in the calculation of lifetime risk of cancer from radiation exposure. Radiat. Environ. Biophys. 52, 135-145 (2013).

45. Alsanea, N. et al. Colorectal cancer in Saudi Arabia: Incidence, survival, demographics and implications for national policies. Ann. Saudi Med. 35, 196-202 (2015).

46. Liauw, S. L., Sylvester, J. E., Morris, C. G., Blasko, J. C. \& Grimm, P. D. Second malignancies after prostate brachytherapy: Incidence of bladder and colorectal cancers in patients with 15 years of potential follow-up. Int. J. Radiat. Oncol. Biol. Phys. 66, 669673 (2006).

47. Nikbakht, H. et al. Latency and interval therapy affect the evolution in metastatic colorectal cancer. Sci. Rep. 10, 1-10 (2020).

48. Halamkova, J. et al. Second primary malignancies in colorectal cancer patients. Sci. Rep. 11, 2759 (2021).

49. Travis, L. B. The epidemiology of second primary cancers. Cancer Epidemiol. biomarkers Prev. a Publ. Am. Assoc. Cancer Res. cosponsored by Am. Soc. Prev. Oncol. 15, 2020 2026 (2006).

50. Arnold, M. et al. Global patterns and trends in colorectal cancer incidence and mortality. Gut 66, 683-691 (2017).

51. Kim, S. E. et al. Sex- and gender-specific disparities in colorectal cancer risk. World J. Gastroenterol. 21, 5167-5175 (2015). 
52. Berian, J. R., Benson, A. B. 3rd \& Nelson, H. Young Age and Aggressive Treatment in Colon Cancer. JAMA 314, 613-614 (2015).

53. White, A. et al. A review of sex-related differences in colorectal cancer incidence, screening uptake, routes to diagnosis, cancer stage and survival in the UK. BMC Cancer 18, (2018).

54. De Gonzalez, A. B. et al. Proportion of second cancers attributable to radiotherapy treatment in adults: A cohort study in the US SEER cancer registries. Lancet Oncol. 12, 353-360 (2011). 